\title{
Do Age of Onset and Course of Illness Predict Different Treatment Outcome among DSM IV Depressive Disorders with Atypical Features?
}

Jonathan W. Stewart, M.D., Patrick J. McGrath, M.D., and Frederic M. Quitkin, M.D., D.M.Sc.

DSM IV defines its atypical features depression modifier mainly by current symptoms. Relative to depressed patients with melancholic features, those with atypical features often present with earlier onset of a more chronic disorder and are less likely to benefit from tricyclic antidepressant (TCA). We, therefore, hypothesized that within depressed patients with atypical features those with illness course most similar to that of melancholia would be most TCA-responsive, those whose illness course least resembled that of melancholia would be least TCA responsive. Two patient groups were treated with TCA, monoamine oxidase inhibitor, or placebo with nonresponders crossed to alternative treatment. One group met DSM IV criteria for atypical features and the other nearly met these criteria. Early onset, chronically depressed patients with DSM IV atypical features had poor TCA response relative to others. Patients with "probable" atypical features (mood reactivity plus one associated atypical feature) and nonresponders crossed to alternate treatment confirmed this. Findings suggest that application of DSM IV atypical features might best be limited to those with early onset of chronic dysphoria.

[Neuropsychopharmacology 26:237-245, 2002]

(C) 2002 American College of Neuropsychopharmacology.

Published by Elsevier Science Inc.
KEY WORDS: Atypical features; Depression; Tricyclic; Monoamine oxidase inhibitor; Age of onset; Course of illness

Atypical depression was incorporated into DSM IV (American Psychiatric Association 1994) as atypical features, a modifier for Major Depressive Disorder and Dysthymic Disorder. Despite demonstrated distinctions between patients with atypical depression and those with melancholia (Quitkin et al. 1985; Bruder et al. 1989; Stewart et al. 1993; Asnis et al. 1995; Rabkin et al. 1996), there is considerable overlap. Thus, while repeated studies demonstrated poor imipramine response rela-

From the New York State Psychiatric Institute, New York, NY.

Address correspondence to: Jonathan W. Stewart, M.D., New York State Psychiatric Institute, 1051 Riverside Drive, New York, NY 10032.

Received 9 February 2001; revised 4 June 2001; accepted 29 June 2001.

Online publication: $7 / 12 / 01$ at www.acnp.org/citations/ Npp071201149. tive to phenelzine, some depressed patients with atypical features still respond to TCA as evidenced by these same studies showing the tricyclic antidepressant (TCA) to be more effective than placebo (Liebowitz et al. 1988; Quitkin et al. 1990). Also, although several biologic parameters differentiate depressed patients with atypical features from those with melancholic features, these parameters are not bimodal and there is considerable overlap among melancholics, atypicals, and controls (Quitkin et al. 1985; Bruder et al. 1989; Asnis et al. 1995). Further, no associated symptom (hyperphagia, hypersomnia, intense lethargy, and rejection sensitivity) better predicted treatment outcome than any other (McGrath et al. 1992), and the associated symptoms do not cluster together (Robertson et al. 1996). Since one might anticipate that the symptoms of a unitary disorder would cluster together, that patients with the same disorder would respond to the same treatment, and that biologically distinct entities would show little overlap in measures of their underlying biology, these re- 
ports suggest that DSM IV criteria for atypical features might define a heterogeneous group of patients. Further delineation of DSM IV atypical features therefore seemed warranted.

Pharmacologic dissection (Klein 1989) posits that differences in response to pharmacologic probes may result from underlying biologic differences. Thus, if depressive subtypes respond differently to the same antidepressant medication, presumably some biologic difference accounts for this. Thus, depressed patients with endogenous symptoms can be expected to respond to TCAs (Bielski and Friedel 1976; Joyce and Paykel 1990), whereas those with atypical features are relatively less likely to respond to TCAs (Liebowitz et al. 1988; Quitkin et al. 1990; Sotsky and Simmons 1999). Thase et al. (1995) argued that these differences imply that depression with atypical features has a different biological basis than does "classical" depression. Nevertheless, some depressed patients with atypical features apparently do well with TCA since TCA was superior to placebo (Liebowitz et al. 1988; Quitkin et al. 1990). To the extent that treatment response depends on underlying biology, there must be an inherent difference between depressed patients with atypical features who respond to TCA and those who do not. If TCA-responsive and TCA-unresponsive subgroups of depressed patients with atypical features have distinct biologies, then other illness parameters might also differentiate these groups.

Besides expected treatment response, patients with atypical features also differ from those with melancholic features in having earlier age of onset of first depressive symptoms (Stewart et al. 1993; Nierenberg et al. 1998), and a more chronic illness subsequent to onset (Stewart et al. 1993). Therefore, age of onset and chronicity were examined to determine whether course of illness might identify subtypes of atypical features using treatment outcome with TCA as a validator. Because depressed patients with melancholic features generally have later onset and a more episodic course relative to those with atypical features, and are more likely to respond to TCA, we hypothesized that among depressed patients having DSM IV atypical features those with early onset of a chronic disorder would be particularly unresponsive to TCA, while those with late onset or episodic course of illness would be TCAresponsive.

\section{METHODS}

Five hundred twenty-seven patients came from among those treated between 1977 and 1995 at the Depression Evaluation Service, an outpatient research clinic of the New York State Psychiatric Institute, who completed a double-blind research study in which they were treated with a TCA, monoamine oxidase inhibitor (MAOI) or placebo. Four patient groups were analyzed. The first group $(N=372)$ included all patients who met Columbia criteria (Liebowitz et al. 1988; Stewart et al. 1993) for definite atypical depression. Columbia criteria for definite atypical depression were incorporated into DSM IV atypical features intact with the added criterion that patients not also meet criteria for melancholic features or catatonia. Patients with DSM III (American Psychiatric Association 1980) or DSM III-R (American Psychiatric Association 1987) melancholia were therefore excluded from the current analyses, so all included patients can be assumed to have met DSM IV criteria for atypical features. The second group $(N=155)$, considered to have "probable" atypical features, also had significant mood reactivity and did not have melancholia, but had specifically one of the four atypical features associated symptoms (Quitkin et al. 1988). The third group consisted of the subgroup of the first two groups who did not respond to six weeks treatment with placebo and then were randomly assigned to double-blind treatment with imipramine or phenelzine $(N=58)$ (Quitkin et al. 1991). The fourth group included those from groups 1 and 2 who had been nonresponders to imipramine or phenelzine and were then treated double blind with the other antidepressant $(N=39)$ (McGrath et al. 1993). We felt justified in combining groups 1 and 2 for these "cross-over" analyses, since both in the current and prior analyses, patients with probable atypical features have behaved similarly to those meeting the full DSM IV criteria (Quitkin et al. 1988; Stewart et al. 1993). Groups 3 and 4 are referred to as "cross-over" groups.

Because our interest was in pharmacologic dissection, patients who did not receive an adequate trial were not included. Thus, the analyses included only patients who took at least three pills a day of TCA (i.e., 150 $\mathrm{mg} / \mathrm{d}), 45 \mathrm{mg} / \mathrm{d}$ of phenelzine or $20 \mathrm{mg} / \mathrm{d}$ of deprenyl, and received at least a four-week trial. Rates of patients not meeting these criteria did not differ between the group having early onset of a very chronic dysphoria and the group with either later onset or less chronic disorder.

Charts of all patients were assessed for age of first dysphoria, age of first Major Depressive Episode, time since most recent well-being, duration of longest wellbeing since illness onset, and an overall estimation of chronicity. Chronicity was measured on a six point scale, rating course of illness since first significant dysphoria: $1=$ single episode $\leqslant$ two years; 2 = recurrent episodes; $3=$ chronic with multiple episodes of wellbeing lasting at least two months each; $4=$ chronic with one or two episodes of well-being lasting at least two months each; 5 = chronic intermittent (i.e., mostly depressed but with multiple days or weeks well, never months); and 6 = chronic persistent (i.e., virtually always depressed, and never two months well). In addi- 
tion, for 122 patients a Course of Illness Form including these parameters had been completed by the evaluating clinician at the initial visit. Charts of all patients were assessed utilizing both the social worker's screening note and the psychiatrist's initial history, but without knowledge of the presence or content of the Course of Illness Form. For patients with a Course of Illness Form, the appropriate data from it were used in the logistic regression analyses, and these patients' chart review data were used to assess the reliability of the chart review process. For patients with only chart review data, these were used in the analyses.

All patients had baseline laboratory work, physical examination and baseline psychiatric ratings, and they signed informed consent. All studies were approved by the Columbia University-New York State Psychiatric Institute Institutional Review Board. There were three studies comparing phenelzine, imipramine and placebo ( $N=108,83$, and 75, respectively) (Liebowitz et al. 1988; Quitkin et al. 1988, 1990), a study comparing deprenyl to placebo $(N=45)$ (McGrath et al. 1989), a study comparing fluoxetine, imipramine, and placebo ( $N=71$ randomized to imipramine or placebo) (McGrath et al. 2000), a study comparing mianserin to placebo ( $N=17$ randomized to placebo) (McGrath et al. 1985), a study comparing imipramine to placebo $(N=$ 99; unpublished data), and a study comparing desipramine to placebo $(N=27)$ (Stewart et al. 1983). Two patients received amitriptyline in a double-blind study comparing mianserin and amitriptyline (Rabkin et al. 1984).

In all studies, placebo was given for one to two weeks, and if still depressed, patients were then randomized to double blind study medication for six weeks. One study lasted 12 weeks (McGrath et al. 2000); six week data were utilized in these patients to maintain consistency across studies. For studies where some patients were assigned medication other than TCA, MAOI, or placebo, only patients who received one of the latter are included here. Since treating clinicians generally had conducted the initial evaluation, they were usually not blind to the patient's clinical course, but evaluators and patients were always blind to treatment assignment. Patients were seen weekly with doses increased weekly or biweekly beginning with $50 \mathrm{mg} / \mathrm{d}$ (all TCAs), $15 \mathrm{mg} / \mathrm{d}$ (phenelzine), or $5 \mathrm{mg} / \mathrm{d}$ (deprenyl) with maximal dose being six pills a day for placebo (eight in the deprenyl study), $300 \mathrm{mg} / \mathrm{d}$ (all TCAs), 90 $\mathrm{mg} / \mathrm{d}$ (phenelzine), or $40 \mathrm{mg} / \mathrm{d}$ (deprenyl). The Clinical Global Impression (CGI) Scale (Guy 1976) was obtained weekly, and the 21-item Hamilton Rating Scale for Depression (Hamilton 1960) was rated at baseline and end of study. Positive response was defined as a CGI Global Impression score of 1 ("very much improved") or 2 ("much improved"). All others were considered nonresponders.
In the three studies comparing imipramine and phenelzine, patients rated a 3 or greater (i.e., "nonresponders") on the CGI Global Improvement Scale were crossed to alternative treatment. Patients not responding were then randomly assigned to alternate blind treatment. Those who had not improved when treated with placebo were randomly treated with imipramine or phenelzine, imipramine nonresponders were switched to phenelzine, and phenelzine nonresponders then received imipramine.

\section{Statistical Analyses}

The first analysis was a Pearson correlation coefficient comparing age of onset and course of illness as determined by chart review vs. the Course of Illness Form completed at the initial interview for 122 patients.

Logistic regression was utilized to determine whether relevant baseline parameters predicted differential treatment outcome. Treatment response (responder/nonresponder) was the dependent variable. Sex (male/female), treatment (TCA/MAOI/placebo), age, age of onset of first dysphoria, course of illness, and study were independent variables. All independent variables were entered simultaneously together with all interactions. Highest order interaction was removed from the logistic regression equation if nonsignificant $(p>.05)$ and the analysis was repeated until at least one significant interaction was found at a given level of interaction and the iterative process was ended. The logistic regression was repeated within the subset ever having had major depression and including onset of major depression as an additional independent variable.

Secondary analyses of group 1 (i.e., those meeting full criteria for atypical features) assessed the Hamilton Depression Rating Scale scores. End study Hamilton was the dependent variable. Covariates were pre-treatment Hamilton, age of onset of first dysphoria, and illness course since onset. Treatment was a grouping factor. Pairwise ANCOVA's investigated any significant findings.

The same logistic regression analyses were conducted in the separate group of 157 patients considered to have probable atypical depression. Rates of response to TCA and MAOI are also shown for the two crossover groups (groups 3 and 4), using $\chi^{2}$ or Fisher's Exact Test, as appropriate. $\alpha=0.05$ was used to assert significance.

\section{RESULTS}

\section{DSM IV Atypical Features}

Three hundred seventy-two patients met DSM IV criteria for atypical features. These included 142 men (38\%) and 230 women $(62 \%)$ with mean age $38 \pm 10$. Most were Caucasian $(88 \%)$ and unmarried $(75 \%$, including $52 \%$ never married). Sixty (16\%) had a history of hypo- 
mania or cyclothymia, $77 \%$ were currently in a major depressive episode and $13 \%$ had never had a major depressive episode. Fifty-nine percent met criteria for dysthymia and $45 \%$ had major depression superimposed on dysthymia [i.e., "double depression" (Keller and Shapiro 1982)]. Mean age of onset of first dysphoria was $16 \pm 12$ years and of first major depressive episode was $23 \pm 12$ years; mean duration since last 2 months of well-being was $187 \pm 168$ months and longest mean duration of well-being since dysphoria onset was $12 \pm 29$ months; mean baseline 21-item Hamilton Depression Rating Scale score was $15 \pm 4$. One hundred and thirtysix had been treated with a TCA (imipramine [mean maximum dose, $261 \pm 52 \mathrm{mg} / \mathrm{d}]=126$, desipramine [mean maximum dose, $267 \pm 66 \mathrm{mg} / \mathrm{d}$ ] $=9$, amitriptyline $250 \mathrm{mg} / \mathrm{d}=1$ ), 86 with a MAOI (phenelzine [mean maximum dose, $69 \pm 16 \mathrm{mg} / \mathrm{d}$ ] $=59$, deprenyl [mean maximum dose, $35 \pm 5 \mathrm{mg} / \mathrm{d}$ ] $=27)$, and 150 with placebo (mean maximum pills, $5.7 \pm 0.8$ pills $/ \mathrm{d}$ ).

Chart review determinations of course of illness parameters generally correlated well with those obtained at initial evaluation using the Course of Illness Form: the two measures of onset of first dysphoria correlated $0.626(p<.001)$, of onset of first major depression .668 ( $p<$ $.001)$, and of 6-point course of illness $0.729(p<.001)$. These were felt to be acceptable and encouraged us to utilize the chart review values for those patients where the Course of Illness Form had not been obtained.

Logistic regression found no four-way or higher interaction to be significant. The only significant threeway interaction was a significant treatment by onset by course of illness interaction (Wald statistic $=6.94, \mathrm{df}=$ $2, p<.04)$. Sex and age were not significant alone or in interaction with other parameters. The significant three-way interaction was accounted for by a significant differences between the MAOI and TCA groups (Wald $=5.79, \mathrm{df}=1, p<.02$ ), and between the TCA and placebo groups (Wald $=4.59, \mathrm{df}=1, p<.04$ ), but there was not a significant three-way interaction involving the MAOI and placebo groups (Wald $=1.20, \mathrm{df}=1$, $p<.3$ ). In the secondary analysis limited to patients ever having experienced a major depressive episode, age of onset of major depression was not significant, either alone or in interaction with other variables, while the interaction involving age of first dysphoria, course of illness and treatment remained significant.

Inspection of the data suggested that patients with onset of first dysphoria prior to age 21 who reported never having experienced well-being lasting as long as two months had particularly poor response to TCA, whereas patients with either later onset (i.e., after age 20 years) or with at least minimal well-being since onset (i.e., at least a single 2-month episode of well-being unrelated to treatment) had as good a likelihood of responding to TCA as to MAOI, both drugs appearing to have superior outcome relative to placebo (see Figure
1). In all groups except those with chronic depression having onset prior to age 20, placebo response was about $30 \%$ and imipramine response approximated $65 \%$, always superior to placebo and approximating phenelzine. The group of patients with chronic early onset depression behaved differently. These patients' imipramine response $(35 \%)$ did not appear to be superior to placebo $(28 \%)$ and was distinctly inferior to phenelzine $(62 \%)$. We hesitate to perform statistical testing since these groups were formed post hoc following inspection of the data, but present the results to clarify the significant interaction found in the logistic regression.

While the main analyses utilized dichotomous response data, they were corroborated by analyses using HAM-D scores. Analysis of covariance with end study HAM-D as dependent variable, baseline HAM-D, age of depression onset and course of illness as covariates, and treatment as grouping variable revealed a significant treatment by onset by course of illness interaction $\left(\mathrm{F}_{2,285}=4.49, p<.02\right)$. Post-hoc analyses showed the same 3-way interaction to be significant when comparing patients treated with TCA to those receiving placebo $\left(\mathrm{F}_{1,223}=6.97, p<.01\right)$ and to those on MAOI $\left(\mathrm{F}_{1,165}=\right.$ $6.10, p<.02)$. MAOI did not differ from placebo on this interaction $\left(\mathrm{F}_{1,181}=.258, p<.7\right)$.

We felt that the demonstration of a significant treatment by age of onset by course of illness interaction in these depressed patients with DSM IV atypical features required confirmation. Three other groups of depressed patients were therefore investigated to determine whether the findings replicated. If the early onset of chronic depression identifies patients with atypical features who will be relatively unresponsive to TCA, then among depressed patients reporting early onset and chronic course those with probable atypical features, and nonresponders who were crossed over to other treatments also ought to be relatively unlikely to benefit from TCA.

\section{Probable Atypical Depression}

Among 155 patients with probable atypical features (depressed patients with significant mood reactivity plus exactly one atypical associated feature), there were 78 females (50\%) and mean age was $38 \pm 11$ years. Sixty-seven percent had current major depression, $63 \%$ dysthymic disorder, and $40 \%$ double depression. Seventy-three were treated with placebo (mean maximum number of pills, $5.6 \pm 1.0$ pills/d), 49 with TCA (imipramine [mean maximum dose, $247 \pm 62 \mathrm{mg} / \mathrm{d}$ ] $=44$, desipramine [mean maximum dose, $265 \pm 55 \mathrm{mg} / \mathrm{d}$ ] = 4; amitriptyline $150 \mathrm{mg} / \mathrm{d}=1$ ), and 33 with MAOI (phenelzine [mean maximum dose, $73.05 \pm 14.7 \mathrm{mg} / \mathrm{d}$ ] $=$ 23, deprenyl [ mean maximum dose, $38 \pm 4 \mathrm{mg} / \mathrm{d}$ ] = 10). Mean age of onset of dysphoria was $15 \pm 12$, onset of major depression occurred at age $22 \pm 12$. Mean baseline HAMD was $14 \pm 4$. Logistic regression re- 


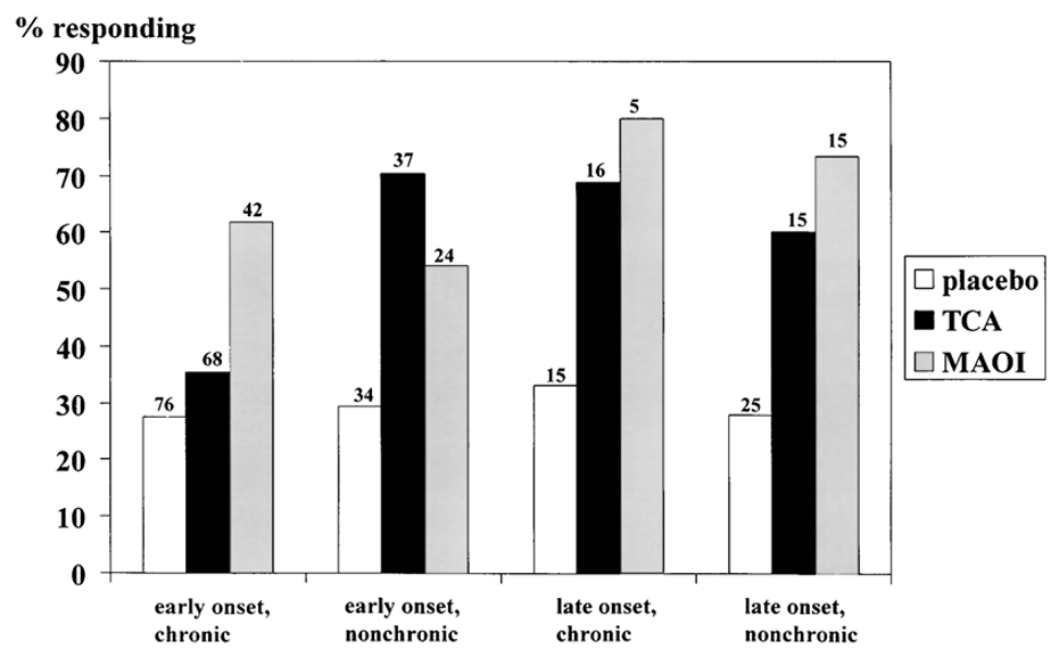

Figure 1. Depressed patients with atypical features. Treatment outcome (\% responding) on phenelzine, imipramine, or placebo, according to onset of first dysphoria and subsequent illness course. TCA indicates tricyclic antidepressant; MAOI indicates monoamine oxidase inhibitor; Early onset indicates onset of dysphoria at or prior to age 20; Late onset indicates onset after age 20; Chronic indicates duration at least two years and no well-being longer than two months subsequent to onset; Nonchronic indicates duration less than two years or at least one episode of well-being subsequent to onset; Numbers above columns indicate the number of patients in each group.

vealed a significant treatment by onset by course interaction (Wald $=4.95, \mathrm{df}=2, p<.05,1$-tailed). Again, placebo response approximated $30 \%$, and in patients who did not report early onset or had not been chronically depressed, imipramine response approximated that for phenelzine and both active treatments were superior to placebo (Figure 2). By contrast, in the early onset chronic group, imipramine response was $43 \%$, was not statistically superior to placebo $\left(\chi^{2}=2.72, p<.1\right)$ and was of benefit to significantly fewer patients than those treated with phenelzine (Fisher's Exact Test, $p=.02$ ).

\section{Cross-over Response in Placebo Nonresponders}

Fifty-eight patients who had not improved when treated with placebo were then randomized to imipramine (mean maximum dose, $249 \pm 61 \mathrm{mg} / \mathrm{d} ; N=$ 30 ) or phenelzine (mean maximum dose, $74 \pm 13 \mathrm{mg} / \mathrm{d}$; $N=28$ ). Again, early onset chronic patients having definite or probable atypical features responded significantly more often to phenelzine $(3 / 13=78 \%)$ than to imipramine $(7 / 18=39 \%$ ) (Fisher Exact Test $p=.04,1$ tailed), and those with late onset or nonchronic illness course responding approximately equally well to either treatment (Fisher Exact Test $p=1.0$, 2-tailed) (Figure 3).

\section{Treatment Refractory Patients}

Thirty-nine patients who had not benefitted from TCA or MAOI were crossed to the alternative treatment, including 13 to imipramine (mean maximum dose, $279 \pm$ $45 \mathrm{mg} / \mathrm{d}$ ) and 26 to phenelzine (mean maximum dose, $74 \pm 15 \mathrm{mg} / \mathrm{d}$ ). Numbers were small, but patients with the early onset of chronic depression with definite or probable atypical features again responded relatively poorly to imipramine ( $38 \%$ responded) and had a fairly good response to phenelzine (61\% responded), whereas the other patients fared fairly well on both treatments (see Figure 4). Statistical testing was considered inappropriate since it cannot be assumed that TCA nonresponders would be equivalent to MAOI nonresponders.

\section{DISCUSSION}

These results show that among depressed patients with DSM IV atypical features, those reporting a chronic depressive illness having onset prior to age 21 responded significantly less often to TCA than did patients who also met DSM IV criteria for atypical features but had either later onset of illness or a less chronic course of illness. These early-onset, chronically depressed patients were not treatment refractory, since many improved when treated with a MAOI. Most compelling, these findings were confirmed in three additional treatment groups: 1) a group of depressed patients nearly meeting criteria for atypical features (i.e., they had mood reactivity plus one of the four DSM IV associated atypical features); 2) placebo nonresponders who were then randomly treated with imipramine or phenelzine; and 3) those initially unresponsive to imipramine or phenelzine who were crossed to the alternative treatment. In all four populations, patients with the early onset of a very chronic disorder responded to imipramine about $40 \%$ of the time, whereas imipramine was effective for at least $60 \%$ of patients with later onset or less chronic illness. In contrast, response to placebo (about 30\%) and MAOI (about 70\%) did not differ much across groups. Thus, pharmacologic dissection (Klein 1989) suggests that depressed patients meeting DSM IV criteria for atypical features whose chronic disorder began relatively early in life may have a different disorder than not only patients with melancholia, but also those with other similar cross-sectional presentation but a less chronic course or later onset. This latter group may 


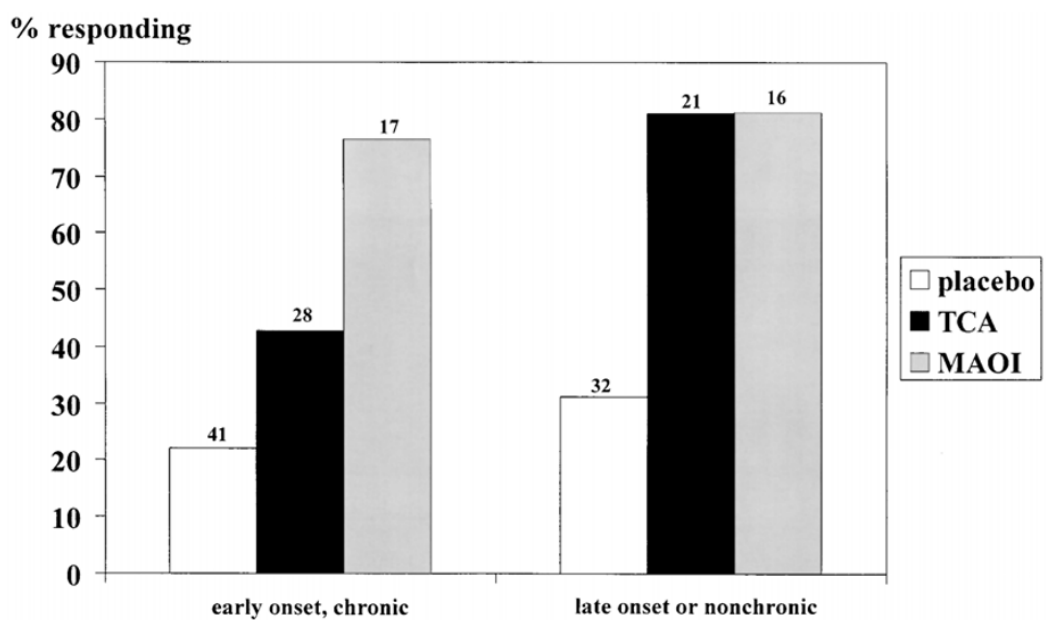

Figure 2. Depressed patients with probable atypical features (i.e., reactivity of mood and one associated symptom). Treatment outcome (\% responding) on phenelzine, imipramine, or placebo, according to onset of first dysphoria and subsequent illness course. Early onset, chronic, and numbers as in Figure 1. Late onset or nonchronic indicates all patients who either did not have early onset or did not have a chronic course of illness. not differ from patients with melancholic features, at least in terms of TCA response.

It appears that age of onset of first dysphoria and not onset of first major depressive episode may best define atypical features. In the current data set, the important issue was the timing of onset of first dysphoria of any kind, and not the life point at which sufficient symptoms were first documented to meet the criteria for major depression. At least among depressed patients meeting DSM IV criteria for atypical features, presence or absence of major depression, or the timing of when it first occurred appears not to be an important predictor of treatment response.

These results parallel the general sense that TCAs are ineffective for children (Geller et al. 1999). Perhaps most childhood onset dysphoria is a different disorder than is later onset depressive disorder. Both the childhood findings and the current data suggest that childhood onset, especially if very chronic, identifies a particularly TCA unresponsive illness.
An earlier report (Quitkin et al. 1988) suggested that patients who have one of the four DSM IV associated symptoms of atypical features may have the same disorder as those who meet strictly applied DSM IV criteria. Depressed patients with significant mood reactivity and exactly one associated symptom were labeled as having "probable atypical features." The current data found an interaction among treatment, onset of dysphoria, and chronicity among patients with probable atypical features. This is partial confirmation both of the importance of these parameters and the similarity between patients meeting full DSM IV criteria for atypical features and those with only one associated symptom.

A monoamine oxidase inhibitor, tranylcypromine, has also been shown to be superior to TCA in treating bipolar patients with anergic depression (Himmelhoch et al. 1991; Thase et al. 1992). These authors defined anergic depression as consisting of major depression plus psychomotor retardation or fatigue, volitional inhibition, and hypersomnia or weight gain. Since mood reac-

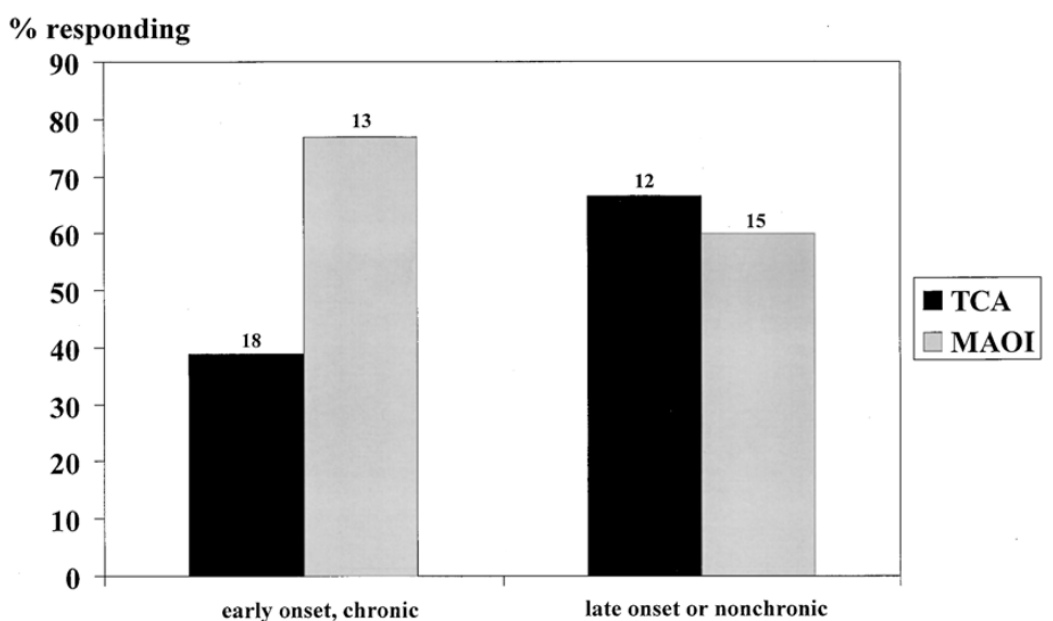

Figure 3. Depressed patients with definite or probable atypical features who did not benefit from six weeks treatment with placebo: Treatment outcome (\% responding) on subsequent phenelzine or imipramine, according to onset of first dysphoria and subsequent illness course. Early onset, chronic, and numbers as in Figure 1 ; late onset or nonchronic as in Figure 2. 


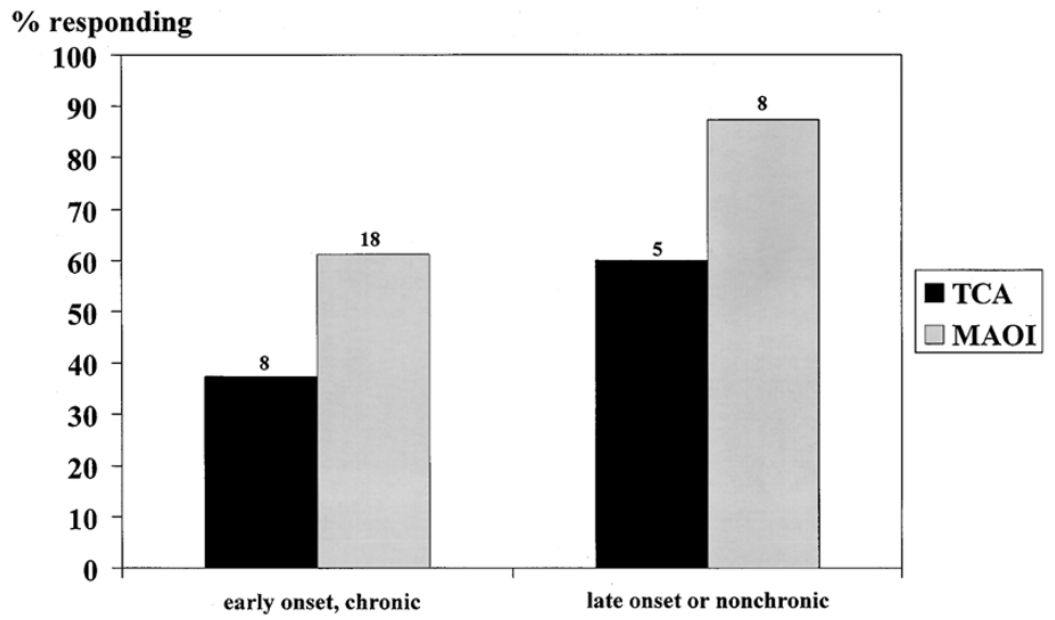

Figure 4. Depressed patients with definite or probable atypical features who did not benefit from six weeks treatment with phenelzine or imipramine. Subsequent outcome (\% responding) when treated with the other medication, according to onset of first dysphoria and subsequent illness course. Early onset, chronic, and numbers as in Figure 1; late onset or nonchronic as in Figure 2.

tivity and rejection sensitivity were not addressed, whether the patients they reported on would have met DSM IV criteria for atypical features is unclear but their required symptoms are suggestive of atypical features. Clearly, neither atypical features nor preferential response to MAOI relative to TCA is limited to patients with bipolar disorder, since most patients in the current study were not identified as having bipolar disorder and, in analyses not shown, the findings applied when patients with bipolar disorder were removed. Further, polarity was not a significant covariate in the over-all analyses. The relationship of atypical features to polarity remains to be determined.

The role of the newer medications in the treatment of depressed patients with atypical features remains to be elucidated. One study compared outcome between phenelzine and fluoxetine, reporting no difference, but risk of a type II error is large (i.e., small sample size made it unlikely that the study would demonstrate a difference between treatments even if one pertained) (Pande et al. 1996). A second study limited to depressed patients with atypical features compared fluoxetine, imipramine, and placebo, finding both drugs effective for about half the patients and both superior to placebo, but not different from each other (McGrath et al. 2000). A large pharmaceutical study comparing sertraline to imipramine to placebo in depressed patients with atypical features has never been published suggesting the possibility that this study also did not distinguish serotonin re-uptake inhibitor from TCA, although this is conjecture. Unlike MAOI, a serotonin re-uptake inhibitor has never been shown superior to TCA in depressed patients with atypical features, but concluding no difference could be prone to type II error. Falkai (1999) asserts the efficacy of mirtazapine for depression with atypical features without any data, and Rye et al. (1998) reported on a single case of apparently late onset atypical depression responding to bupropion. Finally, an unmarketed drug, gepirione, has been demonstrated to be effective for depression with atypical features but no comparison was made with other antidepressant medications (McGrath et al., 1994).

We are unaware of other studies reporting on efficacy of other newer medications in depressed patients with atypical features. Hence, the current literature does not inform us as to whether any of the post TCA/MAOI medications is particularly effective for depressed patients with atypical features. Therefore, the current data are of more theoretical than clinical utility given that few clinicians would consider utilizing TCA or MAOI as a first line treatment. Nevertheless, because the data presented here suggest that biologic differences may exist within patients meeting DSM IV criteria for atypical features, future studies involving depressed patients with atypical features must distinguish between those patients who have early onset of a very chronic dysphoria and those who have either later onset or a more episodic course of illness.

These data should be considered in the context of the limited value that illness course and phenomenology have had in predicting treatment outcome with antidepressants. There have been no recent reviews of predictors of response to second generation antidepressants, and older reviews found virtually no predictors other than the general view that patients with endogenous features respond best to TCA medications (Bielski and Friedel 1976; Joyce and Paykel 1990). Chronicity has generally been found to predict lower response rates to placebo (Khan et al. 1991), and severity of illness predicts greater drug-placebo differences (Brown 1994). However, other than atypical features (perhaps including anergia in bipolars) we know of no replicated predictor that suggests a differential effect among antidepressants. The current analyses suggesting which patients within those with DSM IV atypical features will respond to TCAs and which will not stands out since the initial finding held up in three additional treatment trials. Nevertheless, further investigations are indicated to confirm the utility of age of onset and chro- 
nicity in defining different subgroups within depressed patients with atypical features. Demonstration that distinct subgroups have different underlying biologies would argue for redefining the DSM IV atypical features modifier to only include the subgroup that has distinct biology relative to other depressed patients.

\section{REFERENCES}

American Psychiatric Association (1980): Diagnostic and Statistical Manual of Mental Disorders, 3rd ed. Washington, DC, American Psychiatric Association

American Psychiatric Association (1987): Diagnostic and Statistical Manual of Mental Disorders, 3rd ed, (Revised). Washington, DC, American Psychiatric Association

American Psychiatric Association (1994): Diagnostic and Statistical Manual of Mental Disorders, 4th ed. Washington, DC, American Psychiatric Association

Asnis GM, McGinn LK, Sanderson WC (1995): Atypical depression: Clinical aspects and noradrenergic function. Am J Psychiatry 152:31-36

Bielski RG, Friedel RO (1976): Prediction of tricyclic antidepressant response: A critical review. Arch Gen Psychiatry 33:1479-489

Brown WA (1994): Placebo as a treatment for depression. Neuropsychopharmacology 10:265-269

Bruder GE, Quitkin FM, Stewart JW, Martin C, Voglmaier M, Harrison WM (1989): Cerebral laterality and depression: Differences in perceptual asymmetry among diagnostic subtypes. J Abn Psychol 98:177-186

Falkai P (1999): Mirtazapine: Other indications. J Clin Psychiatry 60(Suppl 17):36-40

Geller B, Reising D, Leonard HL Riddle MA, Walsh BT (1999): Critical review of tricyclic antidepressant use in children and adolescents. J Am Acad Child Adolesc Psychiatry 38:513-516

Guy W (ed) (1976): ECDEU Assessment Manual for Psychopharmacology. Publication ADM 76-338. Washington, DC, US Department of Health, Education, and Welfare, pp 534-537

Hamilton M (1960): A rating scale for depression. J Neurol Neurosurg Psychiatry 23:56-62

Himmelhoch JM, Thase ME, Mallinger AG, Houck P (1991): Tranylcypromine versus imipramine in anergic bipolar depression. Am J Psychiatry 148:910-916

Joyce PR, Paykel ES (1990): Predictors of drug response in depression. Arch Gen Psychiatry 46:89-98

Keller MB, Shapiro RW (1982): “Double depression": Superimposition of acute depressive episodes on chronic depressive disorders. Am J Psychiatry 139:438-442

Khan A, Dager SR, Cohen S, Avery DH, Scherzo B, Dunner DL (1991): Chronicity of depressive episode in relation to antidepressant-placebo response. Neuropsychopharmacology 4:125-130

Klein DF (1989): The pharmacological validation of psychiatric diagnosis. In Robins L, Barrett J (eds), Validity of Psychiatric Diagnosis. New York, Raven, pp 203-216
Liebowitz MR, Quitkin FM, Stewart JW, McGrath PJ, Harrison WM, Markowitz JS, Rabkin JG, Tricamo E, Goetz DM, Klein DF (1988): Antidepressant specificity in atypical depression. Arch Gen Psychiatry 45:129-137

McGrath PJ, Rabkin JG, Stewart JW, Harrison W, Quitkin FM, Markowitz J (1985): Placebo-controlled study of mianserin in depressed outpatients. Neuropsychobiology 14:128-132

McGrath PJ, Stewart JW, Harrison W, Wager S, Nunes EN, Quitkin FM (1989): A placebo-controlled trial of L-deprenyl in atypical depression. Psychopharmacol Bull 25:63-67

McGrath PJ, Stewart JW, Harrison WM, Ocepek-Welikson K, Rabkin JG, Nunes EN, Wager SG, Tricamo E, Quitkin FM, Klein DF (1992): Predictive value of symptoms of atypical depression for differential drug treatment outcome. J Clin Psychopharmacol 12:197-202

McGrath PJ, Stewart JW, Quitkin FM, Wager S, Jenkins SW, Archibald DG, Stringfellow JC, Robinson DS (1994): Gepirone treatment of atypical depression: Preliminary evidence of serotonergic involvement. J Clin Psychopharmacol 14:347-352

McGrath PJ, Stewart JW, Janal MN, Petkova E, Quitkin FM, Klein DF (2000): A placebo-controlled study of fluoxetine versus imipramine in the acute treatment of atypical depression. Am J Psychiatry 157:344-350

McGrath PJ, Stewart JW, Nunes EV, Ocepek-Welikson K, Rabkin JG, Quitkin FM, Klein DF (1993): A double-blind crossover trial of imipramine and phenelzine for outpatients with treatment-refractory depression. Am J of Psychiatry 150:118-123

Nierenberg AA, Alpert JE, Pava J, Rosenbaum JF, Fava M (1998): Course and treatment of atypical depression. J Clin Psychiatry 59(Suppl 18):5-9

Pande AC, Birkett M, Fechner-Bates S, Haskett RF, Greden JF (1996): Fluoxetine versus phenelzine in atypical depression. Biol Psychiatry 40(10):1017-1020

Quitkin FM, Harrison W, Stewart JW, McGrath PJ, Tricamo E, Ocepek-Welikson K, Rabkin JG, Wager SG, Nunes E, Klein DF (1991): Response to phenelzine and imipramine in placebo non-responders with atypical depression: A new application of the crossover design. Arch Gen Psychiatry 48:319-323

Quitkin FM, McGrath PJ, Stewart JW, Harrison W, Tricamo E, Wager S, Ocepek-Welikson K, Nunes E, Rabkin JG, Klein DF (1990): Atypical depression, panic attacks, response to imipramine and phenelzine: A replication. Arch Gen Psychiatry 47:935-941

Quitkin FM, Rabkin JG, Stewart JW, McGrath PH, Harrison W, Davies M, Goetz R, Puig-Antich J (1985): Sleep of atypical depressives. J Affect Dis 8:61-67

Quitkin FM, Stewart JW, McGrath PJ, Liebowitz MR, Harrison WM, Tricamo E, Klein DF, Rabkin JG, Markowitz JS, Wager SG (1988): Phenelzine versus imipramine in the treatment of probable atypical depression: Defining syndrome boundaries of selective MAOI responders. Am J Psychiatry 145:306-311

Rabkin JG, McGrath PJ, Quitkin FM, Fyer A, Stewart JW, Liebowitz MR, Markowitz J (1984): Mianserin versus amitriptyline for depression: A double-blind 6-week trial. Neuropsychobiology 12(4):224-228 
Rabkin JR, Stewart JW, Quitkin FM, McGrath PJ, Harrison WM, Klein DF (1996): Should atypical depression be included in DSM -IV? In Widiger TA, Frances AJ, Pincus HA, Ross R, First MD, Davis WW (eds), DSM-IV Sourcebook, Vol 2. Washington, DC, American Psychiatric Association, pp 239-260

Robertson HA, Lam RW, Stewart JN, Yatham LN, Tam EM, Zis AP (1996): Atypical depressive symptoms and clusters in unipolar and bipolar depression. Acta Psychiatrica Scand 94:421-427

Rye DB, Dihenia B, Bliwise DL (1998): Reversal of atypical depression, sleepiness and REM-sleep propensity in narcolepsy with bupropion. Depress Anxiety 7:92-95
Sotsky SM, Simmens SJ (1999): Pharmacotherapy response and diagnostic validity in atypical depression. J Affect Dis 54:237-247

Stewart JW, McGrath PJ, Rabkin JG, Quitkin FM (1993): Atypical depression: A valid clinical entity? Psychiatr Clin North Am 16:479-495

Thase ME, Mallinger AG, McKnight D, Himmelhoch JM (1992): Treatment of imipramine-resistant recurrent depression. IV. A double-blind crossover study of tranylcypromine for anergic bipolar depression. Am J Psychiatry 149:195-198

Thase ME, Trivedi MD, Rush AJ (1995): MAOIs in the contemporary treatment of depression. Neuropsychopharmacology 12:185-219 